\title{
UNDANGAN PAPERLESS BERBASIS CLOUD COMPUTING DENGAN MEMANFAATKAN CLOUDINARY
}

\author{
Astika Ayuningtyas ${ }^{1}$, Alif Restu Pramudi ${ }^{2}$ \\ Program Studi Teknik Informatika \\ Sekolah Tinggi Teknologi Adisutjipto Yogyakarta \\ astika@stta.ac.id ${ }^{1}$, alif.pramusdi@gmail.com ${ }^{2}$
}

\begin{abstract}
Paperless is an attempt to reduce the use of paper media in the filing process, a use of paperless office technology, paperless office technology will be applied using cloud computing technology. Cloud computing is a service that provides synchronized online storage media, which can be accessed through a variety of devices such as Android smartphones. Cloud services applications built on these systems is a data storage service to take advantage of the cloudinary storage media. Cloudinary is a service that provides cloud services for image, download and CDN (Content Delivery Network). This can certainly provide convenience in the process of registering and sending out invitations electronically using paperless invitations. In addition, there is a process of checking the read (read) status will be performed by the MySQL database system to use the webservice. Paperless invitations applications can be run if the user has an e-mail account, the paperless invitations test system that have been made show the menu each function can be executed according to its input.
\end{abstract}

Keywords: Paperless Invitations, Cloud computing, Cloudinary, Android.

\section{Pendahuluan}

Undangan dibuat dan diterima dalam pembuatannya masih banyak yang menggunakan media kertas. Kertas dibuat untuk membuat undangan yang menyangkut sebuah acara yang akan dihadiri oleh penerima undangan. Jumlah penerima undangan sangat tergantung dari banyaknya anggota komunitas atau masyarakat yang akan diminta hadir dalam acara tersebut. Hal tersebut tentunya membutuhkan media kertas yang tidak sedikit, untuk melakukan penghematan terhadap kertas, dibutuhkan teknologi yang menggantikan media hardcopy menjadi softcopy. Oleh Karena itu perlu dirancang sebuah aplikasi undangan paperless berbasis cloud computing dengan memanfaatkan media penyimpanan dari cloudinary, diharapkan aplikasi undangan paperless tersebut dapat membagikan undangan secara elektronik, sebagai solusi bagi user dalam mengefisiensikan waktu dan biaya pada saat proses pengiriman undangan, serta solusi bagi client dalam mengakses atau membuka undangan, kapanpun dan dimanapun secara online.

\section{Kajian Pustaka}

Menurut Akhmad Syaikhu (2010), dalam jurnalnya menjelaskan tentang Komputasi awan (cloud compuing) perpustakaan pertanian menjelaskan bahwa teknologi yang memanfaatkan layanan internet menggunakan pusat server yang bersifat virtual dengan tujuan pemeliharaan data dan aplikasi sehingga perpustakaan sebagai penyedia layanan informasi dapat memberikan layanan yang terbaik, mutakhir dan berkesinambungan kepada penggunanya.

Menurut Anik Andriani (2013), dalam jurnalnya menjelaskan bahwa Pemanfaatan cloud computing dalam pengembangan bisnis memerlukan biaya untuk pengadaan hardware, software, dan tenaga pengelola tergolong tinggi, perlu solusi untuk mengurangi biaya pengadaan infrastruktur teknologi informasi tersebut tanpa menurunkan kualitasnya upaya yang dapat dilakukan adalah dengan pemanfaatan cloud computing. 
I Gede Putu Krisna Juliharta (2015), dalam jurnalnya meneliti tentang Distribusi konten web server menggunakan metode CDN (Content Delivery Network) yang memungkinkan website di distribusikan pada banyak lokasi agar mampu memberikan kemampuan akses yang cepat, sehingga ketika client mengakses web tersebut data yang diminta dan diterima bukan dari server utama, melainkan dari lokasi $C D N$ terdekat sehingga prosesnya lebih cepat.

Menurut Rusmardiana (2015), dalam jurnalnya menjelaskan tentang Kajian penerimaan teknologi cloud computing pada google drive dalam sistem pembelajaran siswa tingkat smk, untuk kegiatan belajar mengajar peserta didik. Pengenalan teknologi cloud computing seperti google drive dapat diterapkan dalam sistem pembelajaran siswa, dimana siswa diperkenalkan media penyimpanan atau share data melalui jaringan internet atau disebut cloud storage.

\section{Metode Penelitian}

\subsection{Metode pengumpulan data}

Metode yang mengumpulkan data melalui buku-buku, literatur ataupun dokumen yang berhubungan dengan cloud computing yang memanfaatkan cloudinary.

\subsection{Perancangan Sistem}

Layanan undangan paperless berbasis cloud computing ini akan sangat membantu user dalam proses pengiriman undangan secara online, pada sistem yang dikembangkan, layanan cloud terdapat pada aplikasi yang telah ada sebelumnya yaitu Cloudinary CDN (Content Delivery Network). Cloudinary menyediakan API (Application Programing Interface) aman dan komprhensif agar user dengan mudah meng-upload gambar dari sisi server langsung pada browser atau dari aplikasi mobile, agar dapat memudahkan developer dalam membuat, menyimpan dan mengembangkan perangkat lunak untuk sistem operasi tertentu, salah satunya aplikasi undangan paperless sehingga lebih memadai dalam memberikan informasi dan lebih cepat dalam proses pengiriman undangan dan proses pengelolaan undangan yang tersimpan.

\subsubsection{Arsitektur undangan paperlees}

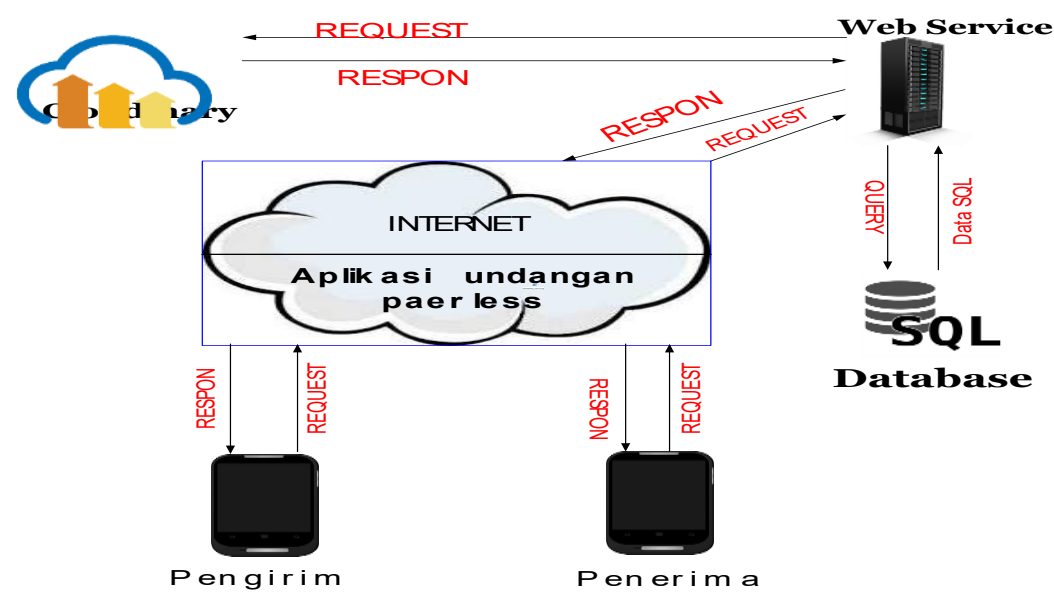

Gambar 1. Arsitektur Sistem

Pada Gambar 1 Undangan yang di-upload atau dikirim oleh pengirim undangan melalui aplikasi undangan papaerless akan tersimpan pada cloudinary sebelum diterima oleh penerima undangan. Melalui Web service diharapkan dapat menampilkan fungsi notifikasi pesan terbaca pada saat undangan tersebut telah di-download atau dibaca oleh penerima yang dilakukan melalui web service dalam bentuk pengambilan data notifikasi pesan di dalam database sql. Data yang dikirimkan dari hasil request pada sistem akan direspon oleh server dan akan diterima oleh pengirim melalui aplikasi undangan paperless berupa status read. 


\subsubsection{Diagram Konteks}

Diagram konteks pada Gambar 2, terdapat alur data dari sistem, terdapat satu entitas yaitu hanya pengguna, pengguna yang dimaksud disini merupakan suatu komunitas pada umumnya dan bagaimana alur sistem dalam gambaran keseluruhan, aliran data pada rancangan diagram konteks ini adalah data dari pengguna dan sistem, akan menampilkan data dari pengguna.

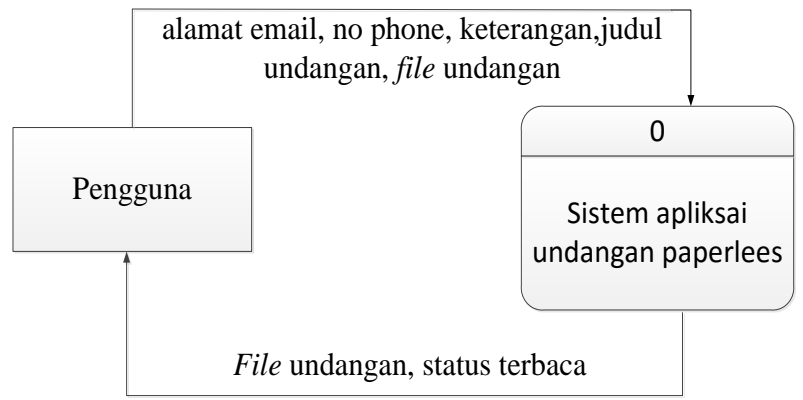

Gambar 2. Perancangan Diagram Konteks

\subsubsection{DFD Level 0}

Diagram ini merupakan gambaran rinci dari proses yang dilakuakan pada diagram konteks yang hanya menjelaskan secara umum proses yang dikerjakan pada aplikasi yang dapat dilihat pada Gambar 3. Pada diagram alir level 0 pada proses 1.P pengguna melakuakn proses registrasi dengan memasukan nama, no phone, dan email, pada proses 2.P pengguna melakukan proses login dengan memasukan data berupa no phone dan email, apabila telah terferifikasi pengguna akan masuk pada halaman utama aplikasi dan akan mendapati halaman kontak dan kirim undangan yang terdapat pada proses 3.P dan 4.P, pada proses 4.P pengguna dapat melakukan upload file undangan yang telah berada pada smartphone dengan format jpg dan pengguna akan diminta untuk memasukan email tujuan, keterangan dan judul undangan. Setelah itu pengguna dapat mengirimkan undangan dengan memilih tombol SEND. Apabila telah terkirim file undangan akan tersimpan terlebih dahulu pada aplikasi Cloudinary pada proses 5.P. Sebelum di terima oleh penerima melalui aplikasi undangan paperlees, file tersebut akan melewati web service tterlebih dahulu pada proses 6.P merupakan proses pengecekan notifikasi terbaca. Ketika pesan telah terbaca maka pengirim akan mendapatkan pesan notifikasi bahwa pesan tersebut telah terbaca dalam bentuk tanggal dan waktu yang sesuai pada saat pesan tersebut dibaca.

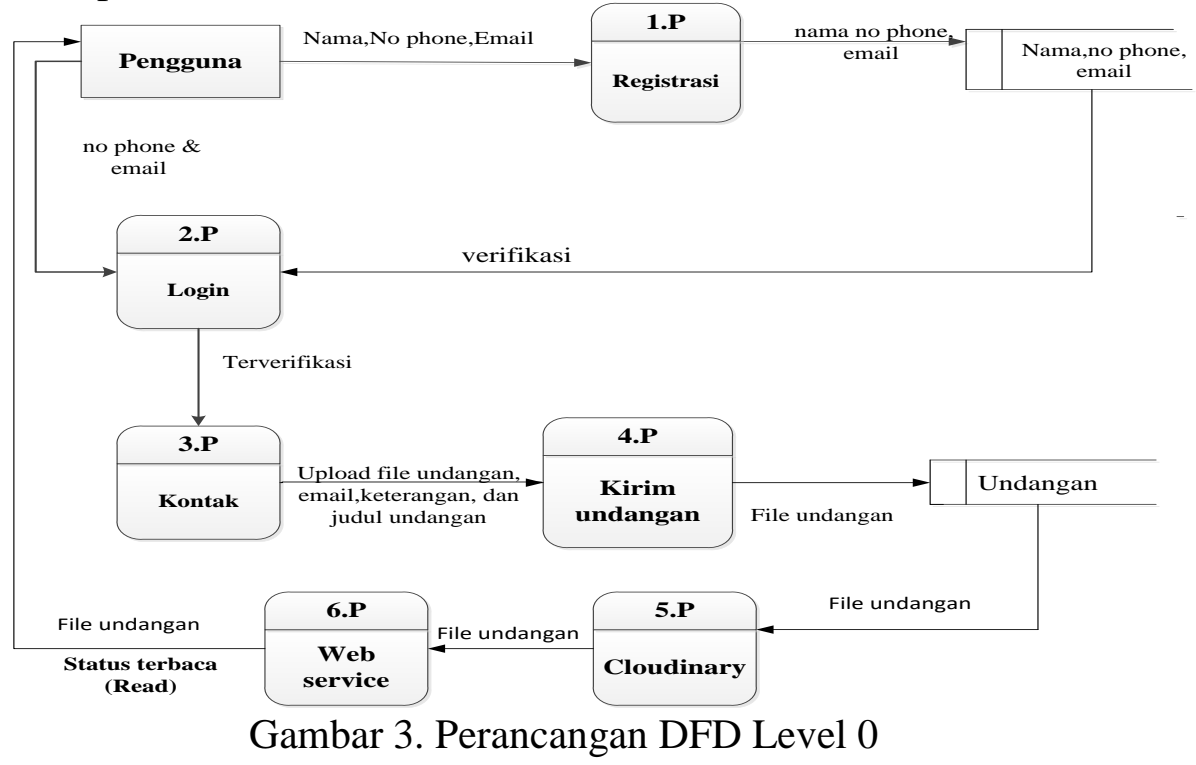




\section{Hasil dan Pembahasan}

\subsection{Pengujian fungsi}

Pengujian fungsi aplikasi undangan paperless yang telah terhubung dengan internet di mana aplikasi tersebut telah ter-hosting sebelumnya. Hasil penguian fungsi perangkat android merupakan jenis pengujian yang telah dilakukan terhadap proses pengiriman undangan berdasarkan ukuran file jpg dan kecepatan internet, kemudian akan di ketahui berapa waktu yang akan dibutuhkan pada saat proses pengiriman file jpg, yang akan dilakukan melalaui beberapa jenis smartphone android.dan akan ditampilkan dalam bentuk Tabel 1 .

Tabel 1. Hasil pengujian prangkat android

\begin{tabular}{|c|c|c|c|c|c|}
\hline No & $\begin{array}{c}\text { Jenis } \\
\text { Smartphone }\end{array}$ & $\begin{array}{l}\text { Ukuran file Jpg } \\
\text { KiloByte-Mega } \\
\text { Byte }\end{array}$ & $\begin{array}{l}\text { Waktu upload } \\
\text { file jpg }\end{array}$ & $\begin{array}{l}\text { Kecepatan } \\
\text { Internet (KiloByte } \\
\text {-Megabyte /second }\end{array}$ & Keterangan \\
\hline 1. & $\begin{array}{l}\text { Samsung Grand } \\
\text { Prime } \\
\text { Android } 4.4 .4\end{array}$ & $\begin{array}{l}69 \mathrm{~KB} \\
1,7 \mathrm{MB} \\
3,0 \mathrm{MB} \\
2,3 \mathrm{MB}\end{array}$ & $\begin{array}{l}\text { 11 Detik } \\
29 \text { Detik } \\
41 \text { Detik }\end{array}$ & $\begin{array}{l}78 \mathrm{~KB} / \mathrm{s} \\
102 \mathrm{~KB} / \mathrm{s} \\
98 \mathrm{~KB} / \mathrm{s} \\
108 \mathrm{~KB} / \mathrm{s}\end{array}$ & $\begin{array}{l}\text { Berhasil } \\
\text { Berhasil } \\
\text { Tidak Berhasil } \\
\text { Berhasil }\end{array}$ \\
\hline 2 & $\begin{array}{l}\text { Samsung Galaxy } \\
\text { A5 } \\
\text { Android } 5.0 .2\end{array}$ & $\begin{array}{l}2,1 \mathrm{MB} \\
3,0 \mathrm{MB} \\
654 \mathrm{~KB} \\
3,9 \mathrm{MB} \\
\end{array}$ & $\begin{array}{l}27 \text { Detik } \\
33 \text { Detik } \\
12 \text { Detik }\end{array}$ & $\begin{array}{l}140 \mathrm{~KB} / \mathrm{s} \\
145 \mathrm{~KB} / \mathrm{s} \\
125 \mathrm{~KB} / \mathrm{s} \\
134 \mathrm{~KB} / \mathrm{s}\end{array}$ & $\begin{array}{l}\text { Berhasil } \\
\text { Berhasil } \\
\text { Berhasil } \\
\text { Tidak Berhasil }\end{array}$ \\
\hline 3 & $\begin{array}{l}\text { Oppo R } 1001 \\
\text { Android 4.2.2 }\end{array}$ & $\begin{array}{l}174 \mathrm{~KB} \\
1,5 \mathrm{MB} \\
3,1 \mathrm{MB} \\
3,4 \mathrm{MB} \\
\end{array}$ & $\begin{array}{l}13 \text { Detik } \\
21 \text { Detik } \\
33 \text { Detik }\end{array}$ & $\begin{array}{l}206 \mathrm{~KB} / \mathrm{s} \\
210 \mathrm{~KB} / \mathrm{s} \\
180 \mathrm{~KB} / \mathrm{s} \\
201 \mathrm{~KB} / \mathrm{s}\end{array}$ & $\begin{array}{l}\text { Berhasil } \\
\text { Berhasil } \\
\text { Berhasil } \\
\text { Tidak Berhasil }\end{array}$ \\
\hline 4 & $\begin{array}{l}\text { Samsung Galaxy } \\
\text { J5 } \\
\text { Android } 6.0\end{array}$ & $\begin{array}{l}518 \mathrm{~KB} \\
1,8 \mathrm{MB} \\
2,6 \mathrm{MB} \\
3,0 \mathrm{MB}\end{array}$ & $\begin{array}{l}26 \text { Detik } \\
43 \text { Detik } \\
52 \text { Detik }\end{array}$ & $\begin{array}{l}82 \mathrm{~KB} / \mathrm{s} \\
94 \mathrm{~KB} / \mathrm{s} \\
89 \mathrm{~KB} / \mathrm{s} \\
92 \mathrm{~KB} / \mathrm{s}\end{array}$ & $\begin{array}{l}\text { Berhasil } \\
\text { Berhasil } \\
\text { Berhasil } \\
\text { Tidak Berhasil }\end{array}$ \\
\hline 5 & $\begin{array}{l}\text { S. Prime G530H } \\
\text { Android } 7.0\end{array}$ & $\begin{array}{l}209 \mathrm{~KB} \\
2,8 \mathrm{MB} \\
3,0 \mathrm{MB} \\
3,3 \mathrm{MB} \\
3,5 \mathrm{MB} \\
\end{array}$ & $\begin{array}{l}\text { 4 Detik } \\
12 \text { Detik } \\
18 \text { Detik } \\
\text { 21 Detik }\end{array}$ & $\begin{array}{l}831 \mathrm{~KB} / \mathrm{s} \\
729 \mathrm{~KB} / \mathrm{s} \\
798 \mathrm{~KB} / \mathrm{s} \\
823 \mathrm{~KB} / \mathrm{s} \\
812 \mathrm{~KB} / \mathrm{s}\end{array}$ & $\begin{array}{l}\text { Berhasil } \\
\text { Berhasil } \\
\text { Berhasil } \\
\text { Berhasil } \\
\text { Tidak Berhasil }\end{array}$ \\
\hline
\end{tabular}

\subsection{Pembahasan}

Pembahasan akan mengurai secara rinci dan menunjukan dokumentasi pengujian fungsi terhadap aplikasi undangan paperless dimana menu write invitation berfungsi untuk meng-upload file jpg serta mengirim file undangan serta proses penerimaan undangan pada aplikasi undangan paperlees dan pengujian terhadap notifikasi pesan terbaca Hasil pengujian yang telah dilakuakan terhadap perangkat android dapat dilihat pada Tabel 1 ukuran file jpg yang dapat di-upload serta dikirim adalah 3,0 MB (Mega Byte). Serta apliaksi undangan paperlees dapat berjalan dan berfungsi sebagaimana mestinya pada smartphone android versi 4.2.2 hingga 7.0.

\subsubsection{Hasil Uji Fungsi Pengiriman Undangan}

Pada pengujian proses pengiriman undangan (Gambar 4) terdapat beberapa form untuk pengguna yang perlu diisi pada saat melakukan pengiriman undangan yaitu choose image yang berfungsi untuk melakukan pengambilan undangan yang tersimpan pada smartphone pengguna dengan ukuran file jpg yang dapat di upload sebesar 3,0 Mega Byte kebawah serta terdapat alamat email yang perlu di isi sebagai tujuan pengiriman undangan serta terdapat judul undangan dan keterangan pesan yang perlu di isi oleh pengguna, langkah selanjutnya pengguna dapat mengklik menu send untuk proses kirim. 


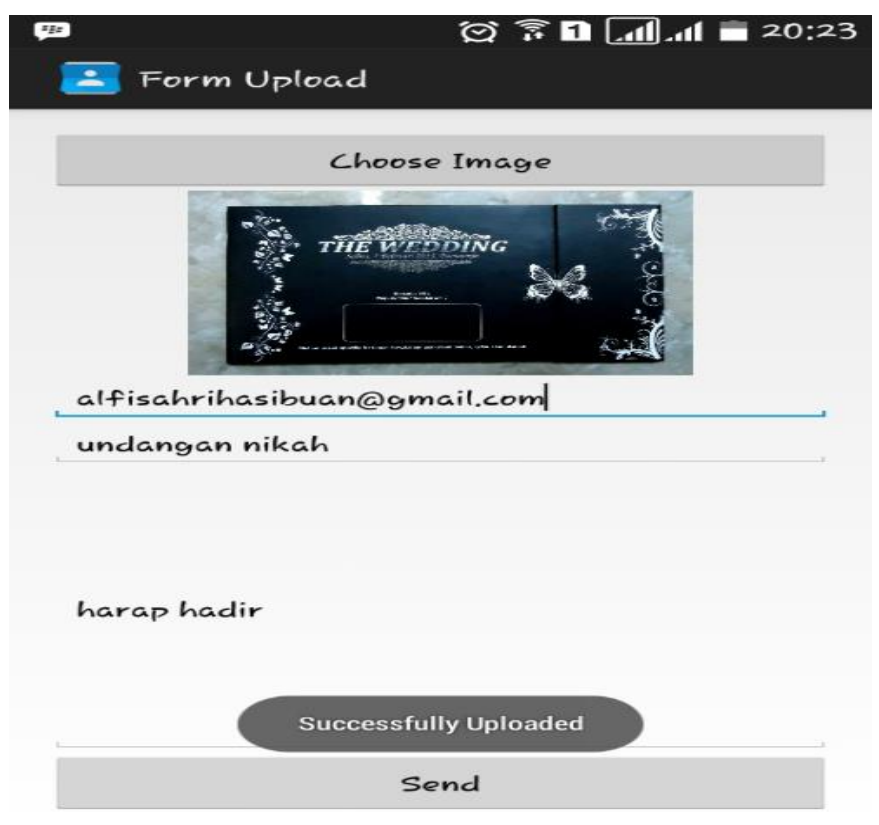

Gambar 4. Uji Coba Fungsi Proses Mengirim Undangan

\subsubsection{Hasil Uji Fungsi PenerimaanUndangan}

Pada halaman inbox di Gambar 5, dimana pesan masuk yang telah dikirim sebelumnya dan telah di terima oleh penerima. Pada saat penerima membuka undangan, secara otomatis akan mendownload undangan tersebut yang telah tersimpan di dalam aplikasi cloudinary yang difungsikan sebagai cloud computing, proses download dilakukan agar notifikasi pesan (read) terpenuhi, yang akan ditampilkan pada menu outbox pengirim undangan.

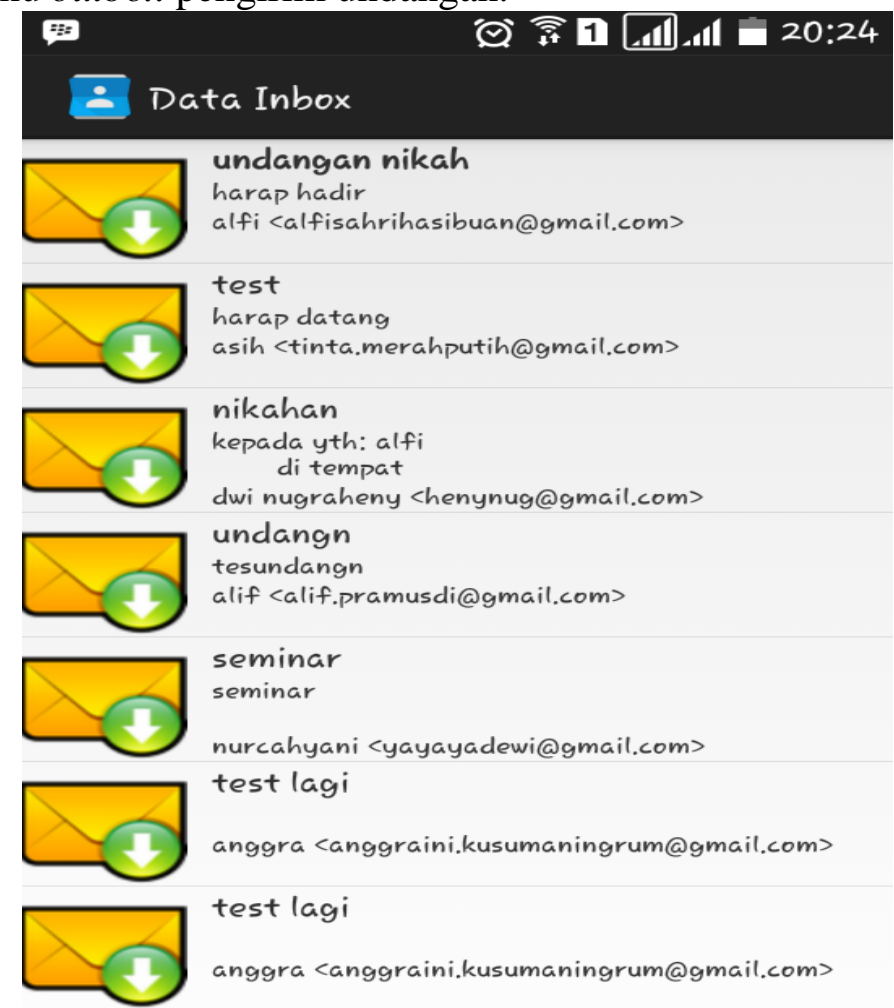

Gambar 5. Uji Coba Fungsi Proses Penerimaan Undangan 


\subsubsection{Hasil Uji Fungsi Notifikasi Status Pesan}

Pada menu outbox (Gambar 6) dari aplikasi undangan paperles, merupakan tampilan dari sebuah laporan pesan keluar yang telah dikirim oleh pengirim serta terdapat tampilan notifikasi status pesan yang fungsinya dapat memudahkan pengguna dalam melihat pesan yang telah terbaca atau belum terbaca

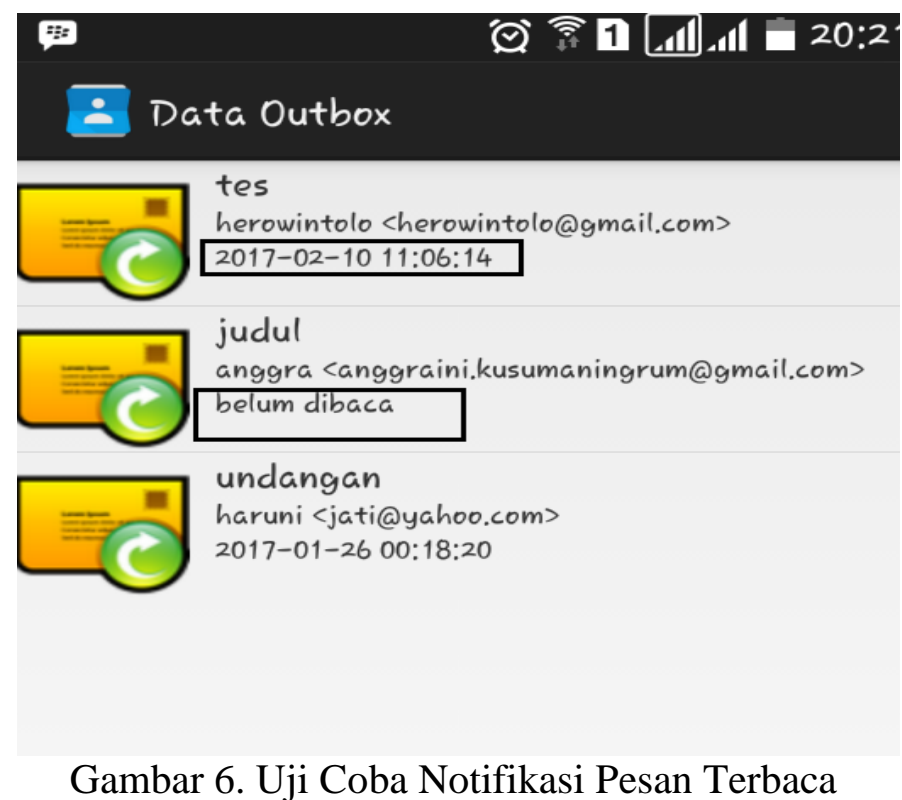

\section{Penutup}

\subsection{Kesimpulan}

Berdasarkan hasil implementasi dan uji coba yang telah dilakukan adalah

1. Aplikasi undangan paperless berbasis cloud computing yang dirancang telah berhasil mengirimkan undangan secara elektronik, sebagai solusi bagi pengguna dalam mengefisiensikan waktu dan penghematan biaya pada saat proses pengiriman.

2. Uji fungsi yang telah dilakuakn terhadap menu aplikasi undangan paperless yang dilakukan oleh dosen STTA berjalan dan berfungsi sebagaimana mestinya.

3. Cloudinary dapat digunakan sebagai media penyimpanan pada sistem aplikasi undangan paperless dalam bentuk format jpg.

4. Aplikasi undangan paperless pada penelitian ini hanya dapat mengirim file jpg ukuran kurang dari sama dengan 3,0 MB, serta dapat berjalan dengan baik apabila di gunakan pada android versi 4.2.2 sampai dengan 7.0.

\subsection{Saran}

Saran untuk penelitian kedepannya berdasarkan hasil penelitian adalah

1. Untuk selanjutnya pada aplikasi undangan paperless berbasis cloud computing dapat dikembangakan agar terdapat notifikasi pesan masuk secara real time serta dapat membuat undangan secara mandiri dalam bentuk format $p d f$ atau $m s c$ word

2. Aplikasi dapat di kembangkan lagi dalam sistem keamanan, baik dari sisi register dan login yang dibuat ter-enkripsi 


\section{Daftar Pustaka}

[1] Andriani, Anik. 2013. Pemanfaatkan Cloud Computing Dalam Pengembangan Bisnis. Jurnal Seminar Nasional Teknologi Informasi dan Multimedia ISSN: 2302-3805, Yogyakarta.

[2] Budiyanto, alex. 2012. Pengantar Cloud computing. Yogyakrta: Komunitas Cloud computing Indonesia

[2] Hero Wintolo, Derry Purnamasari., 2016., Membangun Cloud Computing Memanfaatkan Google Drive Untuk Meningkatkan Layanan Akademik., Prosiding Senatik ISSN 2528166624 November 2016

[3] Irawan, 2012, Membuat Aplikasi Android Untuk Orang Awam, Penerbit Maxikom, Palembang

[5] Juliharta, I Gede, Putu Krisna. 2015. Distribusi Konten Web Server Menggunakan Metode Content Delivery Network. Jurnal Sistem dan Informatika. Vol. 10, No. 1. Bali

[6] M. Syafii, 2004, Membangun Aplikasi Berbasis PHP dan Mysql, Penerbit Andi, Yogyakarta.

[7] Rusmardiana, Ana. dkk, 2015. Kajian Penerimaan Teknologi Cloud Computing Pada Google Drive Dalam Sistem Pembelajaran Siswa Tingkat SMK. Jurnal Seminar Nasional Teknologi Informasi dan Multimedia ISSN: 23023805, Yogyakarta

[8] Syaikhu, Akhmad. 2010. Komputasi Awan (Cloud Computing) Perpustakaan Pertanian. Jurnal Pustakawan Indonesia, Vol.10 No.1 